\title{
Redefining Education with Growth Mindset and Mastery Learning
}

\author{
Rohan Ray
}

\begin{abstract}
This paper analyses whether mastery learning can be effectively amalgamated with the growth mindset into the education system, with a specific lens on technology in India. By presenting successful data studies on the experimental implementation of Mastery Learning in India, it discusses the significance of the findings and highlights the potential drawbacks of widespread adoption of the learning philosophy and its feasibility into reforming the existing education system.
\end{abstract}

Keywords: Growth Mindset, Mastery Learning, Technology, Education

\section{Introduction}

With the passage of time, it has become increasingly noticeable that the educational system has remained largely unaltered with its out-of-date curriculum as it fails to prepare students with adequate skills and knowledge for success after they graduate. In this era of lifelong learning, our current education system fails to create graduates who can self-propel themselves forward. A growth mindset which focuses on continuous growth and learning is nurtured through Mastery leaning. The concept of a growth mindset was developed by Stanford psychologist Carol Dweck and popularized in her book, Mindset: The New Psychology of Success.'In a growth mindset, people believe that their most basic abilities can be developed through dedication and hard work-brains and talent are just the starting point. This view creates a love of learning and a resilience that is essential for great accomplishment," writes Dweck (Dweck, Mindset: The New Psychology of Success). Students who embrace growth mindsets believe that they can become smarter if they work hard and persevere and that they may learn more, and view challenges and failures as opportunities to improve their learning and skills (The Great School Partnership ). Mastery learning is an educational philosophy originally proposed by Benjamin Bloom (Bloom B. S., 1968) that is a proponent ofthe idea of self-paced learning for mastery and not learning for the sole purpose of acing tests. In the theory of Mastery Learning, Bloom proposed the idea, that given sufficient time and adequate conditions, children can attain proficiency in any concerned field. Today technology is at the heart of the future of education. In India, websites such as Khan Academy and Byjus have infused new life into Mastery Learning.

\section{Introduction to the Growth Mindset}

The Growth Mindset was introduced by Stanford psychologist, Carol Dweck. Dweck's research defies the common belief that intelligent people are born smart. As explained by Dweck," A growth mindset is not just about effort. Perhaps the most common misconception is simply equating the growth mindset with effort. The growth mindset was intended to help close achievement gaps, not hide them. It is about telling the truth about a student's current achievement and then, together, doing something about it, helping him or her become smarter." (Dweck, Carol Dweck Revisits the Mindset)
Dweck advises, "If parents want to give their children a gift, the best thing they can do is to teach their children to love challenges, be intrigued by mistakes, enjoy effort, and keep on learning. That way, their children don't have to be slaves of praise. They will have a lifelong way to build and repair their own confidence." (Dweck, Fixed vs. Growth: Understand the two basic mindsets that shape our lives)

A science test was used to measure the initial and final achievement of students. The mastery students took three mastery tests for the six units learnt throughout the experiment. Each unit test had 30 questions for 60 marks. The findings again reveal that students exposed to mastery learning outperformed those exposed to traditional learning techniques, with higher mean achievement and lower standard deviation. Long term treatment in this regard might have brought significant effect on achievement. However, rigorous research is required to reach some definite conclusion

\begin{tabular}{|l|l|}
\hline $\begin{array}{l}\text { Fixed Mindset } \\
\text { Intelligence is static. }\end{array}$ & $\begin{array}{l}\text { Growth Mindset } \\
\text { Intelligence can be } \\
\text { developed. }\end{array}$ \\
\hline $\begin{array}{l}\text { Leads to a desire to look } \\
\text { smart and therefore a } \\
\text { tendency to }\end{array}$ & $\begin{array}{l}\text { Leads to a desire to learn } \\
\text { and therefore a tendency } \\
\text { to }\end{array}$ \\
\hline $\begin{array}{l}\text { - avoid challenges } \\
\text { - give up easily due to } \\
\text { obstacles }\end{array}$ & $\begin{array}{l}\text { - embrace challenges } \\
\text { - persist despite }\end{array}$ \\
\hline $\begin{array}{l}\text { see effort as fruitless } \\
\text { - ignore useful } \\
\text { feedback }\end{array}$ & $\begin{array}{l}\text { see effort as path to } \\
\text { mastery }\end{array}$ \\
\hline $\begin{array}{l}\text { be threatened by } \\
\text { others' success }\end{array}$ & $\begin{array}{l}\text { - be inspired by others' } \\
\text { success }\end{array}$ \\
\hline
\end{tabular}

Figure 1: Fixed Mindset vs. Growth Mindset (Dweck, Fixed Mindset vs. Growth Mindset)

\section{Introduction to Mastery Learning}

Conventional models of education offer little student to student variation in instruction, inflexible timetables, and a disproportionate focus on test score results. Originally introduced (Bloom B. S., 1968) (Bloom B. S., 1976),

\section{Volume 9 Issue 4, April 2020}




\section{International Journal of Science and Research (IJSR) \\ ISSN: 2319-7064}

ResearchGate Impact Factor (2018): 0.28 | SJIF (2019): 7.583

Mastery Learning is a self-paced, customized feedback based educational philosophy. Due to the differing rates of student-to-student information assimilation, allocating fixed time slots for learning is not fruitful. Moreover, time-based learning creates incomplete learning, gaps in knowledge that may surface later as the subject matter increases in complexity. Mastery learning advocates that students can attain expertise in any given discipline contingent on adequate time and personalized instructional techniques, varied to better match individual student learning requirements.

If students are normally distributed concerning aptitude for a subject and if they are provided uniform instruction (in terms of quality and learning time), then achievement level upon completion of the subject is also expected to be normally distributed. This can be illustrated as shown below (Bloom B. ):

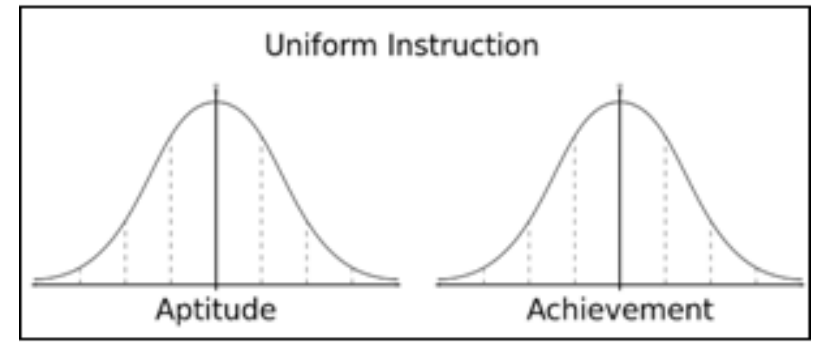

However, Mastery Learning proposes that, if each learner were to receive an optimal quality of instruction and as much learning time as they require, then a majority of students could be expected to attain mastery. This situation would be represented as follows (Bloom B. ):

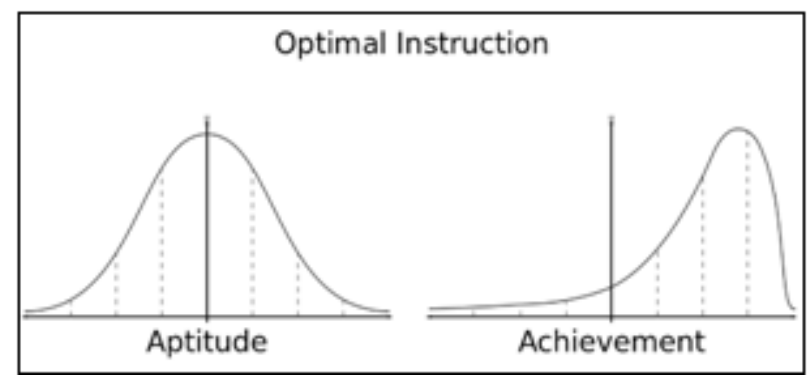

By decomposing material into smaller more discrete lessons with variable time allotments, students can follow a logical progression, learning at their own pace. To proceed to the next lesson, students must be able to demonstrate expertise in the initial lesson (Anderson, 2000). If the student's performance in the formative test indicates that they have not mastered the subject material, they are re-taught, and then re-tested. This circle of teaching, testing, corrective instruction and the summative test continues until mastery has been attained (Block \& Anderson, 1975)

The founder of Khan Academy, Salman Khan, explains why traditional learning strategies fail using an analogy of construction of a home. If the concrete used to define the walls of the house is not allowed sufficient time to dry and the next layers are added on the wet base simultaneously, the structural integrity of the building dismantles (Khan, 2019). Similarly, for a few students, the time allocated to learn certain subject material is suitable, and they can grasp the concept. For the rest of the slower learners, as the time is inadequate, they end up in a haste, resulting in knowledge with many deficiencies. The gaps or holes are carried forward to their advanced studies, and they only accumulate further as content gets more and more cumbersome. However, if the time constraint is removed then the ability to invert the pyramid would be easily feasible, with more creators and entrepreneurs at the top. The key differences between mastery learning and traditional learning models can be summarized in the table below.

Table I: Differences between Mastery and Traditional Learning models (Gupta, 2019)

\begin{tabular}{|c|c|c|}
\hline $\begin{array}{c}\text { Time } \\
\begin{array}{c}\text { Period } \\
\text { and } \\
\text { Testing }\end{array}\end{array}$ & $\begin{array}{c}\text { Every student is taught } \\
\text { subject material in a fixed } \\
\text { time period, after which } \\
\text { they are tested and they } \\
\text { move on to the next topic, } \\
\text { despite gaps in their mastery } \\
\text { of the content }\end{array}$ & $\begin{array}{c}\text { Mastery Learning Model } \\
\text { Stunts can learn at their } \\
\text { own speed, repeating } \\
\text { difficult topics, and } \\
\text { accelerating through easy } \\
\text { ones. They are tested upon } \\
\text { finishing a subtopic and have } \\
\text { to relearn until mastery is } \\
\text { attained }\end{array}$ \\
\hline Syllabus & $\begin{array}{c}\text { A rigid general syllabus } \\
\text { limits the content students } \\
\text { learn throughout the year }\end{array}$ & $\begin{array}{c}\text { A flexible syllabus for } \\
\text { stronger students may allow } \\
\text { them to earn mastery in } \\
\text { topics beyond their peers. }\end{array}$ \\
\hline
\end{tabular}

\section{Data Studies in India}

Data Study 1: Effectiveness of Mastery Learning Strategy Achievement on VII Graders (Science)

This study aimed to investigate the effectiveness of Mastery Learning Strategy and Inquiry Training Model on the achievement of students in Science at VII Grade level, in Rohtak, Haryana affiliated with the CBSE board. The findings from the Inquiry training model are omitted to keep the lens only on the Mastery learning aspect of the study. The students of the control group and the mastery group were equated on intelligence using Cattell's Culture Fair Intelligence Test and then the control group was taught through the traditional learning method, while the experimental group underwent specifically designed mastery lesson plans. A science test was used to measure the initial and final achievement of students. The mastery students took three mastery tests for the six units learnt throughout the experiment. Each unit test had 30 questions for 60 marks. The findings again reveal that students exposed to mastery learning outperformed those exposed to traditional learning techniques, with higher mean achievement and lower standard deviation. Long term treatment in this regard might have brought significant effect on achievement. However, rigorous research is required to reach some definite conclusion. (Kalia, 2005).

Table II: Results from the investigation on the effectiveness of the Mastery Learning strategy on science achievement

\begin{tabular}{|c|c|c|c|}
\hline Group & Number & Mean & Standard Deviation \\
\hline Controlled Group & 30 & 62.80 & 11.85 \\
\hline Experimental Group & 30 & 79.03 & 8.11 \\
\hline
\end{tabular}

Volume 9 Issue 4, April 2020 www.ijsr.net 


\section{International Journal of Science and Research (IJSR) \\ ISSN: 2319-7064}

ResearchGate Impact Factor (2018): 0.28 | SJIF (2019): 7.583

Data Study II: Effectiveness of Mastery Learning on Achievement of IX Graders (Social Science)

Table III summarizes the results from a study on the effect of teaching through a cooperative learning strategy on a sample of 210 (105 in the experimental group and 105in the control group) IX class social studies students from two Government secondary schools of Ludhiana, Punjab, India. The experimental group was exposed to the mastery learning program while the control received the conventional method (lecture and discussion). Performance in test in a standardized social studies test was used for data collection. (Kaur \& Gurmi, 2013)

Table III: Results from the investigation on the effectiveness of the Mastery Learning strategy on social science achievement

\begin{tabular}{|c|c|c|c|}
\hline Group & Mean & $\begin{array}{c}\text { Standard } \\
\text { Deviation }\end{array}$ & $\begin{array}{c}\mathrm{T}- \\
\text { ratio }\end{array}$ \\
\hline Controlled group & 12.82 & 6.43 & $5.82 *$ \\
\hline Experimental Group (Mastery Learning) & 34.39 & 3.50 & $5.82 *$ \\
\hline
\end{tabular}

(*Significant at 0.01 level of significance)

\section{Barriers in widespread adoption and education reform}

It can be argued that personalized teaching can be expensive; however, the pervasiveness of the internet can be a solution. The walls of the classrooms are no longer an impediment as technology enables new ways of learning, communicating, and working collaboratively (Online Purdue Education). Today, accesses to learning opportunities are unparalleled in scope thanks to technology. A colossal amount of data is obtainable at one's fingertips through the web, and opportunities for formal learning are available online worldwide through the BYJUs, Khan Academy, MOOCs, podcasts, and more.

A growth mindset nurtured by Mastery learning has largely proven to be successful in experimental conditions, but the question of whether it is suited for large scale national implementation is yet to be answered. Diagnostic tests, corrective and remedial steps for each unit, and enrichment activities for each unit are an integral part of the learning. Much of the work of Mastery Learning occurs before instruction begins - designing the courses and the content. Once the program is underway and as teachers gain experience and share material and ideas the workload is reduced. In teaching the elements of the learning units, the teachers should allow students adequate time to practise each new skill; provide frequent, regular and direct reinforcement; give students cues to help them select the appropriate responses; see that all students participate actively in the learning tasks; finish direct instruction in the learning task, and monitor each student's work carefully and often. A few foreseeable roadblocks are highlighted below:

1) Quantifying mastery in subjective subject areas: In some humanitarian disciplines such as English and the social sciences due to their subjective nature, it is difficult to measure the degree of achievement.

2) Depth Vs Breadth: In extreme cases, due to time constraints students may not be able to cover the breadth of subjects if they are obsessed with mastering certain topics.

3) Misinterpretation of Growth Mindset: Misinterpretations are that they cause students and adult learners to persist with ineffective learning strategies by obsessing over effort. There is also the question of monotony, and the point where repeating content material becomes futile, being detrimental to the learner's motivation and cognitive development.

4) Ability Stretching: However, with self-paced learning, the elusive question arises, should students simply do as much as they are comfortable with or how would we ensure that students are in fact stretching themselves to their maximum capacity? And in the case of overachievers, will there be an upper limit or can students be expected to go on as far as they want to, and if yes what happens if they go beyond the curriculum that has been planned? These questions are challenging but also are mostly reflective of extreme scenarios, and should not be enough to derail a potential implementation of mastery learning towards the majority (Gupta, 2019).

5) Combining Interpersonal Development and Mastery Learning: A potential concern that could arise is mastery earnings focus on test scores and the question of how to incorporate practical, interpersonal and leadership experiences into mastery learning.

6) Groups of Skill-based Learners: The variable timelines that form the basis of mastery learning could also result in significant age differences in classrooms, and although Bloom theories that with practice, learning rates of slower and faster learners will be equalized, diminishing the gap between individual learning differences, this remains to be seen.

7) Resources, Training and Mindset Shifts: Research suggests that a $95 \%$ mastery rate can be achieved with as little as a 10-20\% increase in instructional effort (Stamatis, 1997). Reeducating and re-skilling the teaching work force to understand the mastery view point would also have to include the cost of changing mindsets and the faith in that all teachers are able to monitor and calibrate the student's progress.

8) Diagnostic Learner and Assessment Tools Needed: For the widespread adoption, the teachers need access to sophisticated diagnostic and assessment tools which are currently available to psychologists and researchers. Classroom trainers need similar tools without access to qualified personnel (Stamatis, 1997).

9) Acceptance / Buy In by stakeholders: The mass restructuring of education would certainly have a ripple effect in the economy and through multiple stakeholders, effects that will certainly not be easy to predict. Would this new learning approach be accepted by all the stakeholders? (Gupta, 2019)

\section{Conclusion}

There is significant experimental evidence highlighting that the mastery learning philosophy nurturing a growth mindset can indeed be successful and that given enough time, every child can learn every topic to a high degree of accuracy. The advantages of mastery learning are apparent and many outweighing the disadvantages, especially in sports and music. The growth mindset leads to better work

\section{Volume 9 Issue 4, April 2020}




\section{International Journal of Science and Research (IJSR) \\ ISSN: 2319-7064}

ResearchGate Impact Factor (2018): 0.28 | SJIF (2019): 7.583

relationships, collaboration, lower stress (Clark \& Sousa) and better interpersonal skills. However, the question is, which model of mastery learning is the best? There may never be a model, which suits all requirements, even procedural, and so needs to be tailored. It is now a question of finding solutions to the more pervasive and unforeseen issues that can come with mastery learning's potential largescale real-world implementation. Governments can help in finding solutions by introducing mastery learning classes as a pilot on a larger scale and recording progress every step of the way. With new technologies and increased internet access to the most remote parts of the globe, personalizing education has never been easier. Learning will occur outside classrooms interactively and will be a life-long endeavor. Technology needs to be paired with interpersonal relationships to become an invaluable asset otherwise we will be generating screen addicts. The role of longitudinal trials, in diverse subject groups across humanities and STEM-based subjects, will be crucial in collecting this and real-world data and achieving successful widespread adoption and reform of the learning philosophy.

\section{References}

[1] Anderson, J. R. (2000). Learning and memory: An integrated approach (2nd ed.). New York: John Wiley and Sons, Inc.

[2] Block, J., \& Anderson, L. (1975). Mastery learning in classroom instruction. New York: Macmillan.

[3] Bloom, B. (n. d.). Mastery Learning. Retrieved from https://en. wikipedia.org/wiki/Mastery_learning

[4] Bloom, B. S. (1968). Learning for Mastery. Retrieved from https://files. eric. ed.gov/fulltext/ED053419.pdf

[5] Bloom, B. S. (1976). Human characteristics and school learning. McGraw-Hill.

[6] Clark, A., \& Sousa, B. (n. d.). Your biggest asset for academic career success? A growth mindset. Retrieved from

https://www.timeshighereducation.com/blog/your-

biggest-asset-academic-career-success-growth-mindset

[7] Dweck, C. (n. d.). Carol Dweck Revisits the Mindset. Retrieved

from https://www.edweek.org/ew/articles/2015/09/23/caroldweck-revisits-the-growth-mindset.html

[8] Dweck, C. (n. d.). Fixed Mindset vs. Growth Mindset. Retrieved

from https://www.quotemaster.org/Growth+Mindset

[9] Dweck, C. (n. d.). Fixed vs. Growth: Understand the two basic mindsets that shape our lives. Retrieved from

https://www.mindsetworks.com/parents/understandingmindset

[10] Dweck, C. (n. d.). Mindset: The New Psychology of Success. Retrieved from https://coachevanburk.com/book-review-mindset-thenew-psychology-of-success-by-carol-dweck/

[11] Gupta, I. (2019). Mastery Learning in the Modern Context. International Journal of New Technology and Research.

[12] Kalia, A. K. (2005). Effectiveness of Mastery Learning Strategy and Inquiry Training Model on Pupil"s Achievement in Science. Indian Educational Review. Retrieved from https://www.it. iitb. ac. in/ vijaya/ticet/dokuwiki/media/inquiry-trainingscience.pdf

[13] Kaur, J., \& Gurmi, S. (2013). Effect of Co-Operative Mastery Learning Strategy on Achievement in Social Studies of IX Graders. International Journal of Science and Research (IJSR).

[14] Khan, S. (2019). Let's teach mastery-not test scores. Retrieved from https://www.ted.com/talks/sal_khan_let_s_teach_for_ mastery_not_tes t_scores?language=en.

[15] Online Purdue Education. (n. d.). How Has Technology Changed Education. Retrieved from https://online. purdue. edu/blog/how-has-technology-changededucation

[16] Stamatis, D. (1997). Chapter 17: Training and Learning Organisation TQM Engineering Handbook Marcel Dekker Inc (Vol.).

[17] The Great School Partnership. (n. d.). The Glossary of Education Reform. Retrieved from https://www.edglossary.org/growth-mindset/ 